\title{
P02-91
}

\section{EPIDEMIOLOGIC INVESTIGATION OF DEPRESSION, ANXIETY, STRESS AMONG IRANIAN COUPLES: A LIFE CYCLE PERSPECTIVE}

\section{E. Bahavarnia}

Shahid Beheshti University, Tehran, Iran

The aim of this study was examining the relationship between demographic variables and epidemiology of depression, anxiety, and stress among 300 Iranian couples (600 individuals). Mean age of sample was 40 (SD: 12.5), using Depression, Anxiety, Stress Scale (DASS) and demographic variables questionnaire. Results of this study show highest rate of stress among women who were in child rearing years. Also highest depression was among men who their wives' have job. One explanation for these results may be that every life cycle stage, has specific problems and stressors. Several studies use the family life cycle approach of grouping a cross-sectional sample into four or five categories that correspond roughly to stages of family development. Most of these studies report U-shaped pattern in which marital happiness in highest during the honey moon stage, lowest when the children are school age or teens, and higher when the children are older or gone (Rollins \& Feldman, 1970). These findings consistent with our results. That is increased stress among mothers might be increased responsibility of mothers in child caring. This research found no stress among fathers in child rearing years. One explanation may because of traditional form of families in Iran. That is males have no companionship with women for child caring. Also this research show that the greater depression in wives', the higher anxiety in husbands'. This might be due to when the wives were depressed, husbands anxiety increase in the light of receive any emotional support from their wives'. 